Брюхова Н.Г., Батуева Н.С., Лычагина Е.Л.

5. Крыласова Н.Б. Отчет о раскопках Плотниковского могильника в Кудымкарском районе Пермского края в августе 2009 г. // Архив МАЭ ПГГПУ.

6. Брюхова Н.Г. Отчет о раскопках Плотниковского могильника в Кудымкарском районе Пермского края в июле-августе 2015 г. // Архив МАЭ ПГГПУ.

7. Бобринский А.А. Гончарство Восточной Европы. Источники и методы изучения. М: Наука. 1978. 272 с.

8. Петрова Н.Ю. Оценка концентрации дробленой раковины моллюсков в формовочной массе глиняных сосудов // Традиции и инновации в изучении древнейшей керамики. Материалы международной научной конференции. СПб: ГЭ, 2016. С. 65-67.

9. Крыласова Н.Б. Отчет о раскопках Плотниковского могильника в Кудымкарском районе Пермского края в августе 2009 г. // Архив МАЭ ПГГПУ.

10. Талицкий М.В. Верхнее Прикамье в X-XIV вв. // Материалы и исследования по археологии. 1951. № 22. М.: Наука. С. 33-96.

11. Брюхова Н.Г. Существование археологического памятника в контексте истории (на примере Плотниковского могильника) // Труды IV (XX) Всероссийского археологического съезда в Казани. Том V Казань: Отечество, 2015. С. 118-120.
12. Голдина Р.Д., Кананин В.А. Средневековые памятники верховьев Камы. Свердловск: УрГУ, 1989. $216 \mathrm{c}$.

13. Савельева Э.А., Истомина Т.В., Королев К.С. Пермь Вычегодская // Археология Республики Коми. М.: ДиК, 1997. С. 561-650.

14. Савельева Э.С. Жигановский могильник. Сыктывкар: Коми НЦ УрО РАН, 2010. 456 с.

15. Савельева Э.С. Ыджыдъёльский могильник. Сыктывкар: Коми НЦ УрО РАН, 2014. 120 с.

16. Иванова Т.В. Редкие виды лепной посуды городища Иднакар // Материалы исследований городища Иднакар. Ижевск: УдИЯЛИ, 1995. С. 72-83.

17. Иванова М.Г. Маловенежский могильник // Средневековые памятники бассейна p. Чепцы. Ижевск: УдИЯЛИ, 1982. С. 52-76.

Статья публикуется при поддержке гранта РФФИ 14-06-96002 р_урал_а Средневековое Пермское Предуралье: меняющееся население в изменяпщцейся среде и в соответствии с Заданием Минобрнауки № 33.1091.2014/K.

\title{
ANALYSIS FUNERARY CERAMICS OF THE PLOTNIKOVO BURIAL GROUND (ON THE BASIS OF THE EXCAVATION 2007-2015)
}

N.G. Bryukhova, researcher of the Department of History, Archaeology and Ethnography

Perm Scientific Center of Ural Branch of the Russian Academy of Sciences, Perm (Russia)

N.S. Batueva, master student of the Chair of Ancient and Middle History of Russia

E.L. Lychagina, candidate of historical sciences,

associate professor of the Chair of Ancient and Middle History of Russia

Perm State Humanitarian Pedagogical University, Perm (Russia)

Abstract. The article analyzes the pottery Plotnikovo burial ground, which belongs to the Rodanovskaya culture. Material culture this time has not been well studied. Finds discovered during the excavations, it was quite diverse. Jewelry, weapon, tools and household items represent it. Some things are similar to the materials of the Russian North, the Volzhskaya Bulgaria and Perm Vychegodskaya.

The study was conducted typological and technological analysis of the fragments of 52 vessels. For the site is characterized by proliferation of cup-shaped vessel with a flattened bottom and a loop handle, weak ornamentation dishes with the prevalence of the use of a comb stamp for applying the patterns, the use of clay in the wet state with the addition of crushed shells in the molding composition. A comparison with ceramic complexes chronologically simultaneous sites Vymskaya and Chepetskaya culture revealed both similarities and differences. These differences indicate the presence of its own tradition of producing ceramics in funerary XII-XV centuries of the population, left the Plotnikovo burial ground.

The study material of the Plotnikovo burial ground is great interest to address the issues of ethno genesis Permian Komis and clarify the chronology of late stage rodanovskaya culture.

Keywords: Rodanovskaya culture; the Middle Ages; ceramics; historical-cultural approach; typological analysis; the shape of the vessels; ornamentation; technological analysis; the original plastic raw materials; molding composition; Perm Cis-Urals; burial ground; Vymskaya culture; Chepetskaya culture.

УДК 94(09)(=15/=9)

\section{БУЛГАРСКИЕ ОЙКОНИМЫ У НАДЖИБА ХАМАДАНИ И АХМЕДА АТ-ТУСИ И ИХ ЛОКАЛИЗАЦИЯ НА ТЕРРИТОРИИ БЫВШЕЙ ВОЛЖСКОЙ БУЛГАРИИ}

(C) 2016

Н.В. Беленов, кандидат педагогических наук, доцент кафедры информационно-коммуникационных технологий в образовании Самарский государственньй соџиально-педагогический университет, Самара (Россия)

Аннотация. В данной статье предпринята попытка локализации крепостей волжских булгар, известных по сведениям средневековых авторов Наджиба Хамадани и Ахмеда ат-Туси; в первую очередь, крепостей Мерджи и Техшу. В ходе решения данной проблемы поднимается вопрос о достоверности сведений указанных авСамарский научный вестник. 2016. № 3 (16) 
торов, а также об общем источнике заимствования этих сведений. Есть веские основания видеть в этом источнике известную среди арабо-персидских историко-географических средневековых рукописей «Рисалию» Ахмеда ибн Фадлана, секретаря аббасидского посольства к эльтеберу волжских булгар Альмушу, побывавшему на Волге в 922 году. Данное положение объясняет как факт отсутствия в приведённых списках известных по другим источникам булгарских городов, так и вопрос уникальности информации Хамадани и ат-Туси. На основе синтеза источниковедческих, топонимических и фольклорных исследований в статье предлагаются варианты локализации некоторых из указанных крепостей и варианты этимологии булгарских ойконимов, упомянутых в трудах рассматриваемых авторов. Обосновывается значимость данных топонимики на современном этапе булгароведческих исследований, особенно в вопросах исторической географии Волжской Булгарии, а также намечаются дальнейшие пути исследований.

Ключевые слова: Волжская Булгария; источниковедение; топонимика; ойконимия; Наджиб Хамадани; Ахмед ат-Туси; Ахмед ибн Фадлан; историческая география; этимология; локализация; арабо-персидские историко-географические рукописи.

Волжскую Булгарию современники называли «страной городов». Археологическими изысканиями вполне подтверждается такое образное именование: на территории, занимаемой ранее волжскими булгарами, к настоящему времени открыто более тысячи укреплённых и неукреплённых поселений различной величины. Вместе с тем нам известны названия немногим более двадцати различных булгарских городов, различной степени достоверности. Часть этих ойконимов упомянута в источниках единично, а некоторые и вовсе известны лишь из фольклора поволжских народов.

Во многом такая ситуация обусловлена тем, что до нашего времени не дошли собственно булгарские исторические источники, о существовании которых у булгар мы знаем из сведений средневековых путешественников, бывавших в Булгаре.

Более того, большинство названий булгарских городов, известных из русских летописей и арабоперсидских историко-географических сочинений, не могут быть однозначно отождествлены с имеющимися археологическими памятниками. Часть булгарских ойконимов упоминается без какой-либо географической привязки, иные сложно отнести именно к булгарской эпохе, поскольку источники хотя и приурочивают их к территории бывшей Волжской Булгарии, но упоминают о них уже после монгольского завоевания.

В связи с этим непреходящую ценность приобретают любые уникальные сведения средневековых источников о городах волжских булгар, основанных до монгольского завоевания. В данной статье предпринимается попытка локализации булгарских крепостей, названия которых известны из трудов Наджиба Хамадани и Ахмеда ат-Туси, авторов XII века. Информация этих авторов, уникальная и не имеющая чётких географических ориентиров, неоднократно интерпретировалась исследователями.

В разное время с различной степенью успеха проблему достоверности сведений указанных авторов, а также локализации и происхождения названий упоминаемых ими булгарских крепостей пытались решить А.И. Артемьев [1], С.М. Шпилевский [2], К.И. Невоструев [3], Н.И. Ашмарин [4], В.Н. Поливанов [5], Г. Ахмаров [6], Ш. Марджани [7], А.П. Смирнов [7], А.Х. Халиков [8], Р.Г. Фахрутдинов [9; 10], Ф.Ш. Хузин [11] и многие другие учёные, в круг научных интересов которых входило изучение истории волжских булгар.

Большинство из них констатировали факт низкой степени достоверности указанной информации, а также её фрагментарности.
Очевидно, что данный вопрос невозможно решить без привлечения, помимо данных исторических источников и археологии, топонимических и фольклорных данных.

История булгаристики знает немало примеров, когда работы в симбиозе над информацией, извлечённой из исторических источников, фольклора и местной топонимии давали блестящий результат. В качестве одного из таких примеров можно привести локализацию Г. Ахмаровым известного по ряду средневековых источников булгарского города Сувара на реке Утке, у села Кузнечиха.

Думается, имеет смысл продолжить изыскания в этих традициях, синтезируя материал из различных областей булгаристики: анализ разноязычных средневековых источников, содержащих сведения о Волжской Булгарии и булгарах; сбор и анализ топонимических данных с территории бывшей Волжской Булгарии; изучение соответствующих разделов фольклора поволжских народов, прежде всего чувашей и казанских татар. Применительно к информации о булгарских крепостях, содержащейся в трудах Наджиба Хамадани и Ахмеда ат-Туси, необходимо осветить следующий круг вопросов. Во-первых, определить общий источник заимствования для данных авторов, вопрос о котором до сих пор остаётся открытым. Вовторых, установить соответствие, насколько это возможно на современном этапе исследований, между перечисленными крепостями Волжской Булгарии и известными археологическими памятниками на её территории. В-третьих, с учётом решения первых двух вопросов, сделать вывод о достоверности сведений Хамадани и ат-Туси, что имеет принципиальное значение для дальнейших исследований.

Надо заметить, что достоверность сведений Наджиба Хамадани и Ахмеда ат-Туси зачастую подвергается сомнениям. Тому есть две основные причины: во-первых, названия четырёх булгарских городов, приводимые у этих авторов, не встречаются более ни в одном источнике; во-вторых, ни Хамадани, ни Туси не упоминают главные города булгар на Волге, известные по другим источникам. Мы предпримем попытку объяснить эти противоречия.

Приведём списки булгарских крепостей у Хамадани и ат-Туси в том виде, как они закрепились в отечественной историографии. Итак, список Хамадани: Йасу, Мерджи, Эрнас, Техшу. Список ат-Туси: Бассов, Мерха, Ернась, Тахасту [12, с. 233]. Нетрудно заметить, что оба списка включают одни и те же названия, различия могут быть объяснены как осо- 
бенностями арабской графики, так и перевода названий на русский язык. Надо отметить, что названия из списка Хамадани, насколько можно судить по косвенным данным, более близки к оригинальным.

Установлено, что оба автора при составлении своих трудов пользовались одним и тем же источником. Ряд исследователей обоснованно, на наш взгляд, полагает, что этим источником была «Рисалия» Ахмеда ибн Фадлана, совершившего путешествие к волжским булгарам в составе багдадского посольства в 921 году [12, с. 395].

В той части труда ибн Фадлана, которая дошла до нас, упоминаний об указанных крепостях не содержится. Однако стоит отметить, что мы располагаем лишь неполным вариантом «Рисалии», даже с учётом обнаружения Мешхедской рукописи. Информация об указанных крепостях вполне могла содержаться в утраченной ныне части источника, сохранившись у Хамадани и ат-Туси в форме компиляций.

Если данное предположение верно и источником сведений о четырёх крепостях в Волжской Булгарии послужила именно «Рисалия», то это может объяснить, почему рассматриваемые ойконимы не упоминаются у большинства других арабо-персидских географов, описывающих земли волжских булгар. Повидимому, дело в том, что эти населённые пункты относились к первым булгарским стационарным поселениям, почему они и попали на страницы столь раннего источника, как «Рисалия», и выполняли роль крепостей. Крупные булгарские города, ставшие известными впоследствии, такие как Булгар, Сувар и Биляр, по всей видимости, ещё не возникли. В этих условиях указанные крепостцы, надо полагать, имели исключительно важное военно-политическое значение для булгар. Спустя несколько десятков лет появились и получили бурное развитие Булгар, Сувар и Биляр, вследствие чего указанные крепости утратили своё значение и перестали упоминаться в источниках.

Археологически существование небольших укреплённых поселений у булгар до X столетия подтверждают раскопки на Самарской Луке и в Ульяновском Поволжье. Возраст таких поселений, по мнению некоторых археологов, может восходить к датировкам памятников новинковского типа [13, с. 42].

Раннее возникновение стационарных поселений у булгар в Среднем Поволжье диктуется и логикой историко-политических процессов того времени. На Среднюю Волгу часть булгар переселилась после того, как их государство в Прикубанье было разгромлено хазарами. Оставшееся там булгарское население было подчинено завоевателями и получило отражённое в русских летописях название «чёрные болгары». Чтобы сохранить независимость, значительная часть булгар расселилась в различных направлениях - на Дунай, Дон и Волгу. Стремительно усилившись, Хазарский каганат в короткие сроки стал контролировать не только Предкавказье, но и Нижнее Поволжье. Таким образом, при ведении чисто кочевого образа жизни, волжские булгары были бы вынуждены вновь попасть в прямую зависимость от хазар. Необходимость нижневолжских и прикавказских земель поволжским кочевникам для круглогодичного кочевания была доказана позднейшими исследованиями над ногайцами и волжскими калмыками. Как известно, в исторических источниках волжские булгары появляются как народ, зависимый от хазар, однако установление этой зависимости, вероятно, надо относить к периоду не ранее второй четверти VIII века. Следовательно, как минимум, некоторая часть булгар должна была оставаться на Средней Волге и в осенне-зимний период. На упомянутых памятниках, а также в некоторых новинковских курганах найдены орудия труда, позволяющие говорить о зачатках земледелия у новинковского населения, что также предполагает наличие стационарных поселений [13].

Возвращаясь к сведениям Хамадани и ат-Туси, отметим, что, по нашему мнению, наиболее уверенно локализуются из их списка булгарских крепостей Мерджи и Техшу.

Название первой крепости, исходя из фонетических особенностей чувашского языка - единственного живого языка булгарской группы, можно гипотетически реконструировать в форме «Мерчи», при этом произносился звук «ч» через мягкую шипящую аффрикату «джь».

Таким образом, можно констатировать, что Наджиб Хамадани в данном случае передал звучание булгарского ойконима с большой точностью.

Теперь перейдём к вопросу локализации Мерчи/Мерджи. Среди современных населённых пунктов сёл с таким названием мы не найдём. Однако, согласно информации В.Е. Симакова - известного самарского краеведа-чувашеведа, село Аксубаевского района республики Татарстан, известное сегодня как Новое Мокшино, исторически называлось - и продолжает так именоваться местными старожилами - Меречень (упоминаемый иногда вариант Мерезень - то же название, только на место «з» правильнее было бы поставить «Дж») [14, с. 145]. По некоторым данным, имеется и речка с таким названием. То есть в данном случае имеем классическую для волжско-булгарской топонимии схему: от древнего города остаётся одноименный гидроним (принадлежащий незначительной реке или ручью), который дублируется названием лежащего в его окрестностях населённого пункта. Археологическим памятником, соответствующим булгарскому Мерчи, вероятно, является Новомокшинское городище. Данный памятник представляет собой расположенное на мысу между рекой и, вероятно, ранее обводнённым оврагом укрепление, небольшой, по булгарским меркам, площади - немногим более полутора гектар. Можно отметить солидные фортификационные сооружения на памятнике двойную линию валов и рвов. Кроме того, обращает на себя внимание значительная толщина культурного слоя на Новомокшинском городище - в среднем 60 сантиметров. Учитывая, что городище является именно крепостью, или, по устоявшейся классификации булгарских древностей, феодальным замком, на что указывает его небольшая площадь и внушительная линия укреплений, - такая толщина культурного слоя свидетельствует о значительной древности её сооружения и длительном функционировании именно как военного объекта. Для сравнения, большинство булгарских крепостей либо имеет культурный слой мощностью до 30 сантиметров, либо не имеет его вовсе. По всей видимости, когда прилегающая к крепости местность стала относительно безопасной для селе- 
ний открытого типа, возникли обширные посады, общей площадью более 15 гектар.

Название данной крепости можно этимологизировать из чувашского «Мерчен» со значением «сказочный, легендарный» либо «жемчужный, коралловый» $[15$, с. 337$]$. Во втором случае, по-видимому, обозначение можно рассматривать как синоним к эпитету «великолепный». Заметим, что подобные эпитеты для городов Волжской Булгарии засвидетельствованы (сравните, например: «Шам-Суар», «Нур-Сувар» по отношению к городу Сувару, что означает «Блистательный Сувар», «Сияющий Сувар»).

Крепость Техшу/Тахасту локализовать сложнее. Вероятнее всего, речь в данном случае идёт об одном из известных из других источников булгарских городов - Тухчине или Тетюше. О местоположении города Тухчина среди историков нет единого мнения, известно лишь, что он находился в центральных областях Волжской Булгарии. Данный ойконим известен из русских летописей, в рамках повествования о большом походе против волжских булгар русских князей в 1183 году. С.М. Шпилевский считал возможным объяснять название города от имени местного эмира, о котором, впрочем, в источниках нет ни единого упоминания, если не считать полулегендарного правителя Волжской Булгарии с именем Тука. Мы же считаем, что этимологически название данного города, вероятно, восходит к этноплеменной тюркской группировке «тухси», известной, прежде всего, в Центральной Азии. Они традиционно связываются с тюргешами и считаются выходцами из их этноплеменного союза. Данные о языке и обычаях тухси приводятся Махмудом Кашгарским, для которого проживание тухси в окрестностях Иссык-Куля и в Чуйской долине было современной реальностью [16]. Исходя из сведений об их языке, тухси могут быть классифицированы как народ, говоривший на одном из огузских тюркских языков. Какие-либо данные о масштабной миграции представителей этого племени на запад отсутствуют. Однако родовые подразделения с таким именем фиксируются источниками и у кыпчаков - например, Токсобичи русских летописей. Также известно об аккумуляции представителей различных этноплеменных групп на территории Волжской Булгарии на протяжении всей её истории, в том числе из Центральной Азии [17]. Кроме того, происхождение ойконима от этнонима - распространённая традиция в волжско-булгарской топонимии: такую этимологию имеют ойконимы Булгар, Сувар, Биляр и, вероятно, Ошель, что также, на наш взгляд, свидетельствует в пользу данной версии.

Однако, если наше предположение верно и название Тухчин действительно восходит к этнониму «тухси», то из вероятных прототипов крепости Техшу этот город следует исключить. Дело в том, что процесс кыпчакизации Волжской Булгарии берёт начало с XI столетия, что было связано с распадом Кимакского каганата и продвижением кимако-кыпчакских групп населения на запад. До этого времени говорить о каком-либо кыпчакском влиянии на территории Волжской Булгарии нет никаких оснований. Следовательно, в источник первой четверти X века кыпчакское название проникнуть не могло.

В этой связи ещё больший интерес приобретает второй кандидат на прототип булгарского Техшу -
Тетюши. В окрестностях современного города археологами выявлены могильники IX-X веков, как языческие, так и раннемусульманские. Тетюшское II городище, расположенное на мысу с местным названием «Вшивая горка», восходит ещё к поселениям именьковской культуры, и, вероятно, оно являлось одним из первых стационарных поселений Волжской Булгарии. Интересную гипотезу о происхождении топонима Тетюши выдвинул Е.П. Казаков. Он возводит ойконим к угро-мадьярскому слову «tetu» со значением «вошь, насекомое», что хорошо согласуется с местным народным названием городища. Стоит отметить, что значительная роль угорского населения в формировании волжских булгар в свете последних исследований получает всё большее подтверждение [18, c. 109]. О присутствии древних венгров в Поволжье свидетельствуют как арабо-персидские, так и собственно венгерские средневековые источники. Более того, присутствие угорского этнического компонента в Среднем Поволжье и в Приуралье прослеживается вплоть до монгольского нашествия [19]. Вопрос об археологическом подтверждении пребывания угорских племён на Волге и участии их в этногенезе населения Волжской Булгарии был подробно рассмотрен Е.А. Халиковой на материалах Больше-Тиганского и Танкеевского могильников [20].

Материалы дальнейших исследований подтвердили предположения о значительной роли угорского этнического компонента в истории Волжской Булгарии и этногенезе булгар. Наиболее значительным это влияние было на ранних этапах истории булгар на Волге, то есть в тот период, к которому мы и относим возникновение у них здесь первых крепостей. Таким образом, угорская этимология части булгарских ойконимов, в частности рассматриваемого нами «Техшу», может быть признана вероятной. В новейшей историографии вопрос об угорском влиянии на историю и культуру Волжской Булгарии наиболее полно освещён в цитированной работе Е.П. Казакова [18]. Учитывая вышесказанное, на данный момент наиболее вероятным вариантом локализации крепости Техшу нам представляется городище «Вшивая горка» в окрестностях города Тетюши. Данный вопрос, разумеется, нуждается в дальнейших исследованиях, которые должны будут включать как анализ окрестной микротопонимии, так и интерпретацию археологических материалов - в частности, с известного Тетюшского могильника.

Вопрос о местоположении двух других крепостей - Йасу и Эрнаса - на основании тех данных, которыми мы располагаем на данный момент, однозначно разрешён быть не может. Вместе с тем считаем возможным высказать некоторые предварительные догадки по данной теме. Прежде всего, необходимо отметить, что, как нам представляется, положительное решение вопроса о существовании и локализации крепостей Мерджи и Техшу повышают доверие к сведениям Хамадани и ат-Туси, а также делают небезосновательными надежды на подобное решение и относительно Йасу и Эрнаса. Хотелось бы, однако, отметить один факт. Исследователями, практически с момента появления в научном обороте сведений о крепости Йасу, делались предположения по поводу отождествления этого ойконима с этнонимом «ису/вису», встречающемуся в источниках для обо- 
значения одной из северных народностей, с которыми булгары вели торговлю. По нашему мнению, если такое отождествление верно, то речь здесь скорее может идти об ошибке одного из авторов либо компиляторов, чем о существовании в столь ранний период у булгар форпостов в северных землях. Торговля с северными народами составляла важнейший источник доходов булгар и определённо началась до посещения их земель ибн Фадланом. Вместе с тем сведения о стационарных пунктах волжских булгар на Верхней Каме и её притоках появляются в источниках только в ордынское время. Археологические исследования остатков таких факторий позволяют датировать их основание домонгольским временем, но не столь ранним, как начало X века [21, с. 17]. С некоторой долей вероятности название крепости можно было бы связать с этнонимом северной народности в том случае, если бы она, допустим, была расположена на торговом пути, ведущем на север, или в ней базировались бы склады с вывезенной оттуда пушниной. Однако всё это пока лишь догадки, не подкреплённые фактами. Кроме того, разнообразие форм написания ойконима, среди которых встречаются и такие, как «Яхассну», «Бахассну», также делают такое отождествление сомнительным.

С крепостью Эрнас ситуация ещё сложнее. В данной связи можно привести лишь догадку Н.И. Ашмарина, который указывал деревню с названием Арняш в Мамадышском уезде Казанской губернии. Но сам автор гипотезы был весьма осторожен в предварительных выводах [4]. От себя добавим, что появление в рассматриваемый период булгарских укреплений к северу от Камы, по нашему мнению, маловероятно, хотя данный вопрос, безусловно, нуждается в более детальном исследовании.

Перед тем, как перейти к выводам, хотелось бы отметь, что перспективы дальнейших изысканий в данном направлении, на наш взгляд, лежат в продолжении комплексных исследований на территории бывшей Волжской Булгарии, включающих в себя всесторонний анализ топонимических данных (как бытующих в настоящее время, так и извлечённых из архивных материалов), фольклорных и этнографических материалов, данных археологии. Сказанное в равной мере относится как к предварительно локализованным в данной статье объектам, так и к тем, вопрос о локализации которых пока остаётся открытым.

В связи с вышеизложенным, считаем уместным сформулировать следующие выводы:

1. Подтверждение сведений Наджиба Хамадани и Ахмеда ат-Туси относительно крепостей Мерчи/Мерджи и Техшу/Тахасту повышает доверие к информации, содержащейся в этих источниках, и позволяет надеяться, что в ходе дальнейших исследований будут локализованы и отождествлены с соответствующими археологическими памятниками и другие крепости из их списков - Йасу и Эрнас (в варианте Наджиба Хамадани). На современном этапе исследований можно лишь предполагать, что они, как и две локализованные крепости, по-видимому, должны располагаться на территориях, освоенных булгарами на ранних этапах своего пребывания в Поволжье. В связи с этим этимология ойконима Йасу от известного по источникам этнонима «ису/вису» представляется маловероятной.
2. Оригинальность сведений Наджиба Хамадани и Ахмеда ат-Туси, по-видимому, обусловлена тем, что они опирались на сведения Ахмеда ибн Фадлана, содержавшиеся в не дошедшей до нас части «Рисалии», о ранних крепостях Волжской Булгарии, которые вскоре после этого утратили своё значение и исчезли со страниц историко-географических трудов. Произошло это вследствие возникновения и развития других крупных городских центров Волжской Булгарии, таких как Булгар, Сувар, Биляр и Ошель. Также определённую роль в отсутствии упоминаний этих ойконимов у других арабо-персидских авторов и в русских летописях сыграло и расширение границ булгарского государства на Волге, вследствие чего указанные крепости оказались в центральной, относительно безопасной его части.

3. На современном этапе исследований считаем возможным отождествить крепость Мерджи/Мерчи с Новомокшинским городищем, известным у окрестного населения как «Меречен», а Техшу/Тахасту со II Тетюшским городищем в окрестностях современного города Тетюши на правом берегу Волги.

\section{СПИСОК ЛИТЕРАТУРЫ:}

1. Артемьев А.И. Исторические сведения о Казанской губернии // Список населённых мест по сведениям 1859 года. XIV. Казанская губерния. СПб., 1866. $344 \mathrm{c}$.

2. Шпилевский C.M. Древние города и другие булгарско-татарские памятники в Казанской губернии. Казань, 1877. 489 с.

3. Невоструев К.И. О городищах древнего Волжско-Болгарского и Казанского царств в нынешних губерниях Казанской, Симбирской, Самарской и Вятской. М., 1871.350 с.

4. Ашмарин Н.И. Болгары и чуваши. Казань, 1902. 202 c.

5. Поливанов В.Н. Археологическая карта Симбирской губернии. Симбирск, 1900. 204 с.

6. Ахмаров Г.Н. Экскурсия на место древнего Сувара // Изв. Общ-ва археологии, истории и этнографии. Казань, 1893. № 7. С. 478-481.

7. Смирнов А.П. Волжские булгары. М.: Наука, $1951.453 \mathrm{c}$.

8. Халиков А.Х. Монголы, татары, Золотая Орда и Булгария. Казань: ФЭН, 1994. 103 с.

9. Фахрутдинов Р.Г. Очерки по истории Волжской Булгарии. М.: Наука, 1984. 216 с

10. Фахрутдинов Р.Г. Археологические памятники Волжско-Камской Булгарии и её территории. Казань: Таткнигоиздат, 1975. 219 с.

11. Хузин Ф.Ш. Булгарский город в Х - начале XIII вв. Казань: Мастер-Лайн, 2001. 477 с.

12. Крачковский И.Ю. Арабская географическая литература/Избранные сочинения. Том IV. М.: АH CCCP, 1957. $965 \mathrm{c}$.

13. Матвеева Г.И. Могильники ранних болгар на Самарской Луке. Самара: Самарский университет, 1997. 226 c.

14. Симаков В.Е. Энциклопедия чувашских сёл Самарской области. Самара: НТЦ, 2008. 405 с.

15. Федотов М.Р. Этимологический словарь чувашского языка. Чебоксары: Изд-во ЧГИГН, 1996. 696 с. 
16. Махмуд Кашгарский. Диван лугат ат-тюрк. Алматы, 2010. 589 с.

17. Беленов Н.В. «Чёрные клобуки» в Волжской Булгарии // Народы Евразии. История, культура и проблемы взаимодействия. 2012. № 15. С. 198-203.

18. Казаков Е.П. Волжские болгары, угры и финны в IX-XIV вв.: проблемы взаимодействия. Казань: Институт истории им. Ш. Марджани, 2007. $208 \mathrm{c}$.

\section{NAJIB HAMADANI AND AHMED AT-TUSI'S BULGARIAN OIKONYMS AND THEIR LOCATION IN THE FORMER VOLGA BULGARIA}

(C) 2016

N.V. Belenov, candidate of pedagogical sciences, associate professor of the Chair of Information and Communication Technologies in Education Samara State University of Social Sciences and Education, Samara (Russia)

Abstract. This article attempts to localize the fortresses of the Volga Bulgars (first of all, fortresses Marj and Tehshu) known from medieval authors reportedly Najib Hamadani and Ahmed at-Tusi. In the course of solving this problem the question of these authors' data reliability is raised, as well as the common source of this information borrowing. There is a good reason to see this in the source known among the Arab-Persian historical and geographical medieval manuscripts as «Rizal» by Ahmed ibn Fadlan, the Secretary of Abbasid embassy to the Volga Bulgars Elteber Almush, who visited the Volga in 922. This fact explains the absence of Bulgarian cities known from other sources in the given lists as well as the question of uniqueness of Hamadani and at-Tusi's information. On the basis of the sources synthesis, place-and folklore studies, the article proposes some options for localization of some of these forts and etymology options of Bulgarian oikonyms mentioned in the papers by the considered authors. The author proves the importance of place names data at the present stage of Bulgar study research, especially of Volga Bulgaria historical geography as well as further studies are planned.

Keywords: Volga Bulgaria; source study; toponymica; Najib Hamadani; Ahmed at-Tusi; Ahmed ibn Fadlan; historical geography; etymology; localization; Arab-Persian historical and geographical manuscripts.

УДК 93

\section{ЭПИДЕМИОЛОГИЧЕСКОЕ СОСТОЯНИЕ РОССИЙСКОЙ ИМПЕРИИ: ИСТОРИЯ ИЗУЧЕНИЯ В ОТЕЧЕСТВЕННОЙ НАУКЕ И ПРАКТИКЕ}

(C) 2016

Д.М. Мифтеева, аспирант кафедры истории России

Оренбургский государственный педагогический университет, Оренбург (Россия)

Аннотация. В данной статье рассматривается история изучения эпидемических заболеваний в отечественной науке, проанализированы основные тенденции становления эпидемиологии как науки в России. Показана значимость деятельности ученых-практиков в борьбе с инфекционными заболеваниями в предыдущие столетия, положительный опыт которых является базисом современной науки эпидемиологии. Борьба с инфекционными заболеваниями в предыдущие столетия имела неоднозначный результат. С одной стороны, отечественными и зарубежными эпидемиологами были достигнуты выдающиеся результаты в лечении и профилактике инфекционных заболеваний, что позволило существенно снизить показатели заболеваемости и смертности в XX-XXI вв. Вместе с тем, современный период в истории характеризуется совокупностью социальных и экономических изменений: ростом городов, интенсивностью миграции, трансформация затронула также и возрастную структуру населения стран мира. Все перечисленные факторы привели к изменению одной из основных характеристик большинства инфекционных заболеваний - ограниченности территориальной локализации. В XXI в. тенденции распространения эпидемий на значительные расстояния, могут привести к возникновению масштабных пандемий в пределах одной или нескольких стран. На сегодняшний день учеными наблюдается всплеск новых и неизвестных до этого времени заболеваний таких как: атипичная пневмония (SARS), свиной и птичий грипп (H1N1 и H5N1), вирус Эбола, ближневосточный респираторный синдром (MERS) и т.п. Отмечается возврат уже ликвидированных инфекций: тиф, холера, желтая лихорадка и т. п. Данные процессы показывают, что человечеству предстоит пройти еще значительный путь к полной победе над инфекционными заболеваниями, а изучение опыта достигнутого в предыдущие столетия ученымиэпидемиологами, позволит внести существенный вклад в эту неравную борьбу человека с вирусом.

Ключевые слова: инфекционные заболевания; эпидемиологическая ситуация; экологический фактор; эпизоотии; территориальная локализация; отечественная историография; Российская империя; древнерусские летописи; противоэпидемические мероприятия; государственная политика; отечественная медицина; чума; холера; оспа; малярия; исторический опыт; распространение; микробиология; профилактика. 